\title{
ALGAE AND BUILDING FAÇADE REVISITED. A STUDY OF FAÇADE SYSTEM FOR INFILL DESIGN
}

\author{
Widjaja MARTOKUSUMO ${ }^{a}$, M. Donny KOERNIAWAN', Heru W. POERBO ${ }^{c}$, \\ Nissa A. ARDIANI ${ }^{\mathrm{d}}$, Susan H. KRISANTI ${ }^{\mathrm{e}}$ \\ Department of Architecture, School of Architecture, Planning and Policy Development, \\ Institut Teknologi Bandung, Jalan Ganesha 10, 40132 Bandung, Indonesia

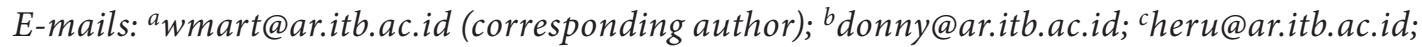

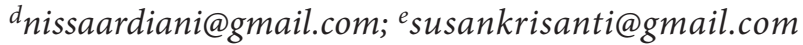

Received 26 August 2017; accepted 21 November 2017

\begin{abstract}
Buildings account for around 30 percent of the world's total energy consumption and a similar percentage of the world's greenhouse gas emissions the main cause of climate change. The building sector is a major energy consumer, and empirical research reveals that carbon-dioxide emissions from the building sector exceed those of the industry and transport sectors. Contextual juxtaposition has commonly been applied in designing a new building in the historic district. In the realm of design, such philosophy-based design approach requires objective measurements. When new glass building considered, the question on greenhouse gas emissions becomes significant. To minimize energy consumption and reduce sun glare, brise-soleil and horizontal fixed shading devices have been used as elements of building's façade. Nowadays, algae as part of building façade system have been used in creating a healthier indoor environment. This paper is written based on an on-going architectural design-based research on the use and role of algae as part of the building façade system. The new building of ITB Innovation Park is used as an infill project. With the help of modelling and extensive literature survey, this research will investigate how far the building (façade) design is affected by considerations on energy consumption pattern and environmental condition.
\end{abstract}

Keywords: algae, building façade system, contextual juxtaposition, historic district, ITB Innovation Park.

\section{Introduction}

As one argues, buildings account for around 30 percent of the world's total energy consumption and a similar percentage of the world's greenhouse gas emissions as the main cause of climate change (Wen et al. 2007). The building sector is a major energy consumer, and when embodied energy is considered, empirical research reveals that carbon-dioxide emissions from the building sector exceed those of the industry and transport sectors (U.S. EIA 2017). The construction and operation of a building contributes importantly to resource depletion and greenhouse gas emissions (Kim 2013). There is a significant challenge for building design, construction industries and building owners to be able to provide healthy indoor environments without depleting non-renewable energy resources and contributing to air pollution and global warming.
In the realm of design, the discourse on surrounding new building in the historic setting has been important for decades (Schmidt 2008). Without a doubt, there has always been a fear that the sense of place and identity of a historic area might be ignored or negatively affected if new buildings are added (Riza, Doratli 2015). Furthermore, recently there has been a more increasing awareness of historic preservation and a shift toward area-based conservation (Tiesdell et al. 1997). All of those have been accompanied by a growing awareness of the need to be able to design new buildings (infill) that are well-matched with historic buildings. Thus, the notion of "fitness" among new and old building is extensively discussed between experts and scholars, such as architects, planners, designers, theorists, historians, critics, and preservationists (Riza, Doratli 2015). Together with that, the notion of "contextualism" has become a permanent subject in the architectural liter- 
ature (Sotoudeh, Abdullah 2013). Harmony with the context is the main concern of any integration into a historic setting. Nevertheless, the integration "does not require a slavish adherence" to the architectural style of the existing context (Carmona et al. 2010). Following this, the new building should be "differentiated" from the existing historic fabric, but "compatible" with the historic materials, features, size, scale, and proportion (Weeks, Grimmer 1995). They both also noted that massing or envelope of the new building may contribute to protect the integrity of the property and its environment (Orbașli 2008; Wells 2010).

As part of heritage conservation strategy, contextual juxtaposition has commonly been applied in designing a new building in the historic urban quarter (Riza, Doratli 2015; Wohlleben, Meier 2003). In the realm of architectural design, such philosophy-based design approach may require objective measurements. When new glass building is considered, the question of greenhouse gas emissions becomes significant (Kim 2013). To minimize energy consumption and reduce sun glare, the way that building façade is designed will be important. Some precedents show the use of brisesoleil and solar fixed shutters/shading device as an integrated building façade element.

To create healthier indoor environment, nowadays algae as part of building façade system has recently been introduced and used, especially when the façade is dominated by a transparent surface. The use of algae as part of the building façade system - produces neither waste nor pollution. On the contrary, algae can produce fast-growing biomass that can be harvested daily (ur- ban farming) (Stone 2012). Algae integrated building envelopes are not a new concept in the architecture field (Kim 2013). Several architects and designers have used algae in their conceptual buildings or in art installations. The HOK's first place winning scheme for the 2011 IDEAS competition showed an algae photo-bioreactor tube attached to the top surface of the opaque building envelopes of the GSA federal building in Los Angeles. In addition to this project, their recent concept design of the net energy zero Battery Park project in San Francisco incorporated algae photo-bioreactor panels to grow algae and reduce $\mathrm{CO}_{2}$. Furthermore, the BIQ house in Hamburg, Germany belongs to the world's first algae façade integrated building, and it is also enclosed with algae panels as the shading device.

The primary objective of this research is to carry out a study of a comparison of three different building façade systems, i.e. the use of brise-soleil, transparent with horizontal fixed shading device and algae photo-bioreactor. This paper will discuss the preliminary performance assessment of those façade systems in relation to indoor temperature and total energy use.

\section{Method}

This paper is written based on an ongoing research project on building façade system. The building façade system deals with the ITB Innovation Park project, a new building (infill) project in the historic urban quarter. The new building is located close to ITB campus on Jalan Ganesha, which has been designated as a historic district in Bandung. Regarding the design approach, contextual juxtaposition has been chosen as

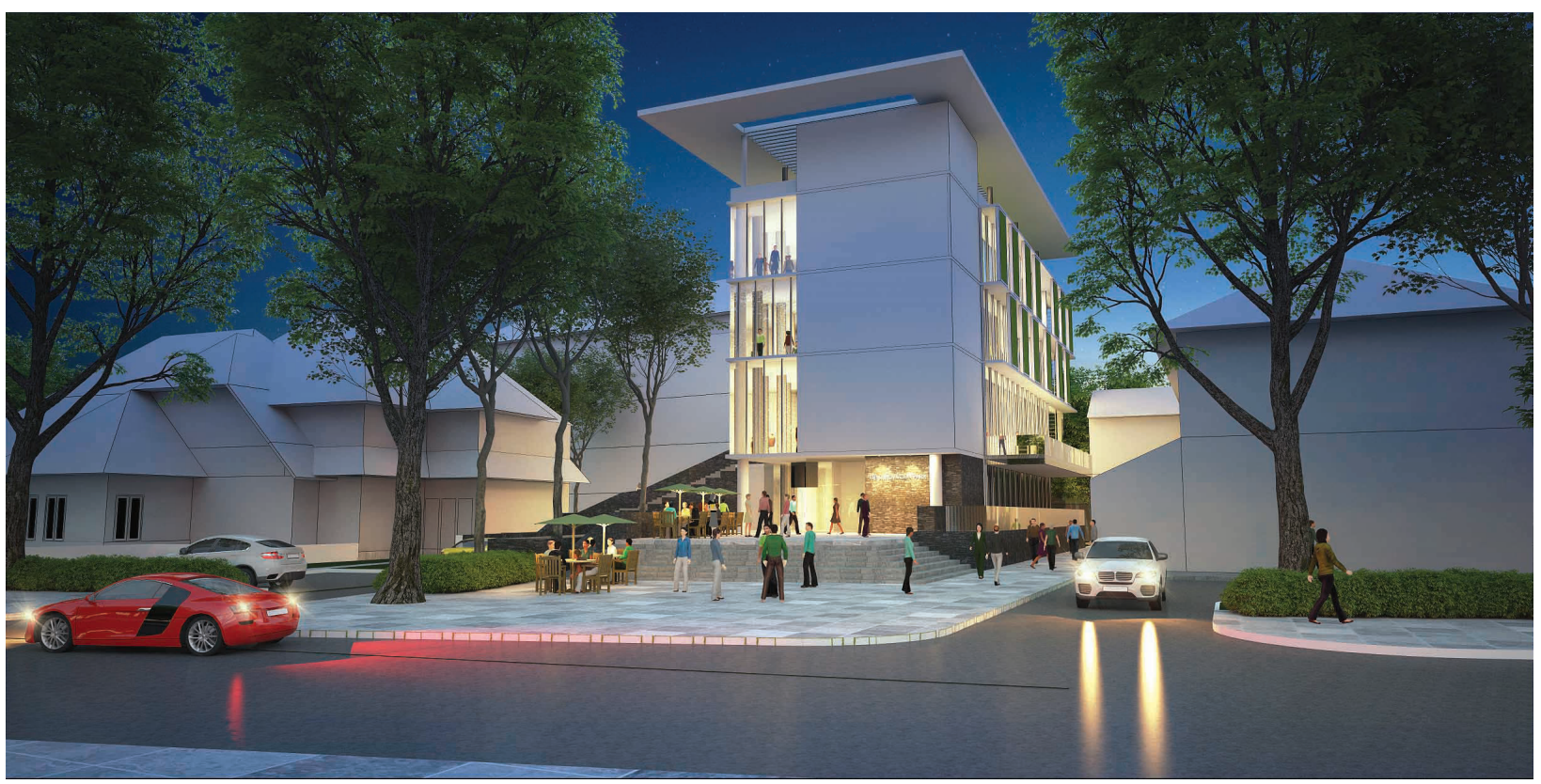

Fig. 1. The design of ITB Innovation Park on Jalan Ganesha 
the strategy for the new building to create a harmony between the old and the new building. Nevertheless, such philosophy-based design approach may require objective measurements (Yeang 2008, 2006).

When new glass building is considered, the question of greenhouse gas emissions becomes significant. To minimize energy consumption and reduce the sun's glare, the way that building façade is designed will be important. The building has a north-south orientation, with the transparent/glass façade on its west and east sides (see Fig. 1). The experiments will primary be simulated in a simplified model (e.g. Fig. 2). Three types of building façade will be compared and evaluated. The first building façade uses the brise-soleil (see Fig. 3a), the second uses horizontal fixed shading device (see Fig. 3b), and the third alternative employs the algae photo-bioreactor (see Fig. 4a, Fig. 4b). The experiment on algae photo-bioreactor will be simulated in a direct experiment, while the first two are based on computer simulation. Through computational modeling (Open Studio-Energy Plus/OS-EP software), the two alternatives of building façades, i.e. brise-soleil and horizontal shading device will be tested, except for the third façade alternative. In the Open Studio-Energy Plus software, Singapore weather data will be used as the basis for the simulation since there is still a lack of Indonesia weather data. Through this simulation model, the data of inside temperature and total consumed energy will also be measured and digitally recorded.

Following the computer simulation for building façade with brise-soleil and fixed horizontal shading device, some experiments of algae photo-bioreactor were performed in stages as follows: 1) temperature measurement, 2) illuminance test and 3) calculation of the amount of oxygen $\left(\mathrm{O}_{2}\right)$ release. Temperature measurement is needed to indicate the temperature differences $(\Delta \mathrm{T})$ between indoor and outdoor temperature. The temperature differences for the brise-soleil and horizontal shading device are calculated through computer simulation. For direct measurement of algae the data were digitally collected through two data loggers, which were installed inside and outside of the simplified model of photo-bioreactor. The photo-bioreactor itself was filled with algae (chlorella) with its medium and nutrient. The experiment had lasted for 24 hours.
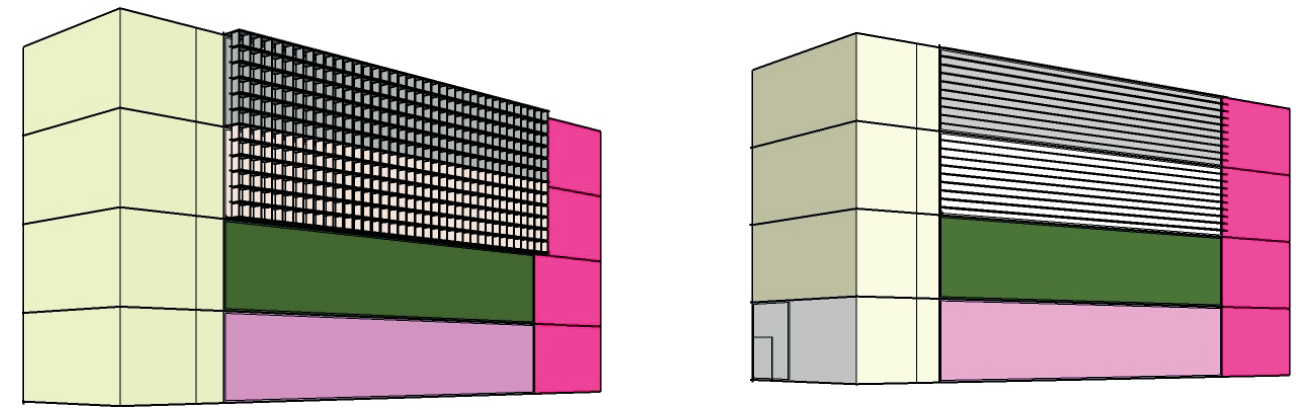

Fig. 2. Simplified model of ITB Innovation Park with two types of shading devices
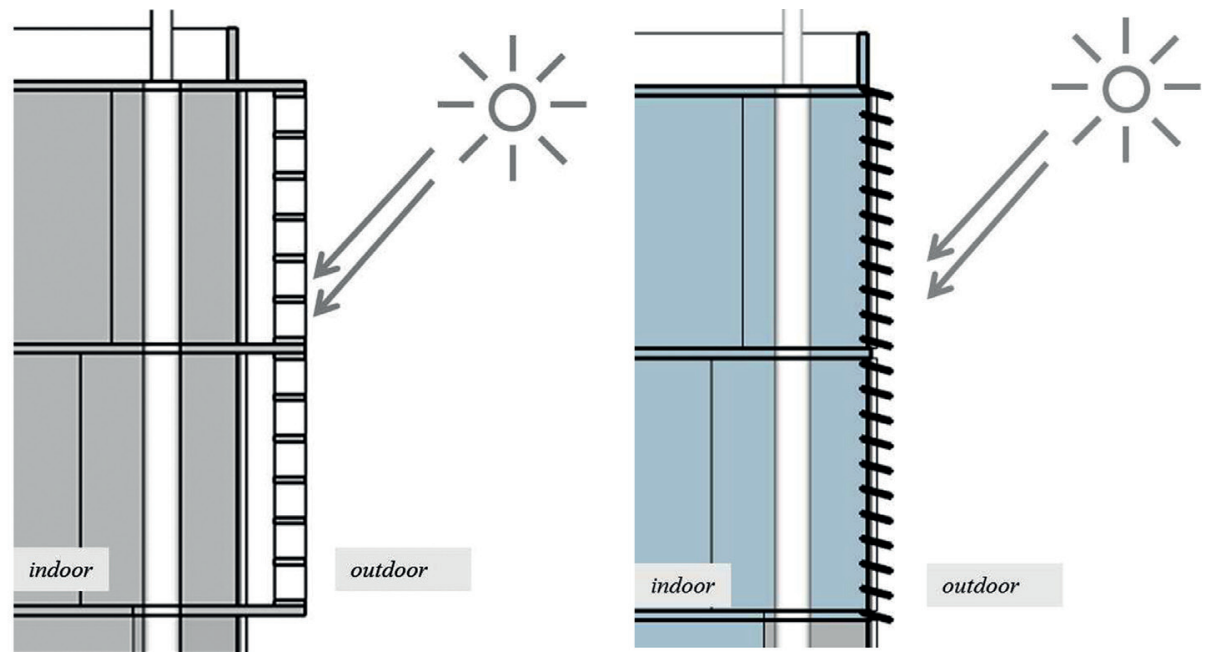

Fig. 3. Section on the left shows the application of brise-soleil and on the right, the horizontal fix device in the building façade 


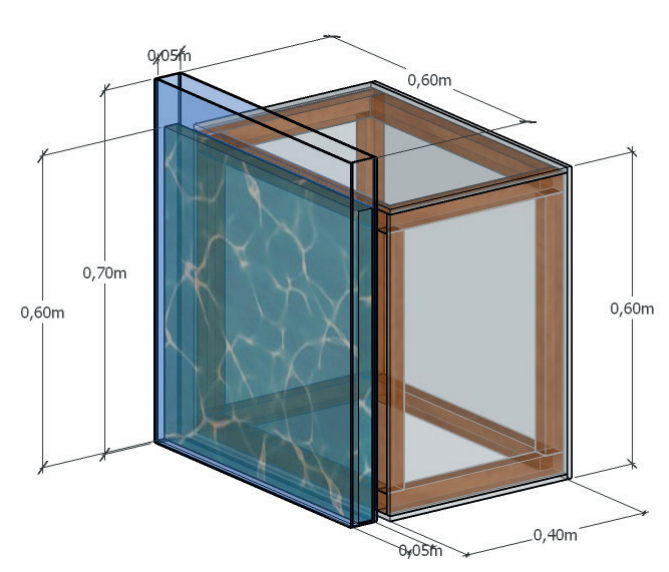

Fig. 4a. The model of algae photo-bioreactor

Illuminance test is generally conducted to gain the amount of luminous flux per unit area. Through direct measurement data illuminance is recorded, and furthermore compared and analyzed according to the standards (SNI 2001). For office work the minimum requirement is 350 lux (SNI 2001), while another type of activity, such fine drawing workshop requires up to 750 lux. In relation to that, the measurement of the indoor irradiance value could contribute to increase the ability of algae photo-bioreactor in reducing solar heat gain. Furthermore, that will have a significant impact on the use of energy. Following this, it can thus confirm the ability of the algae photo-bioreactor and property material to absorb the solar radiation.

Oakley has done a comprehensive monitoring of photosynthetic performance $\mathrm{CO}_{2}$ and $\mathrm{O}_{2}$ flux, as well as photosynthetic electron transport in microalgae of aquatic organisms (Oakley et al. 2012). The measurement of oxygen $\left(\mathrm{O}_{2}\right)$ release in this experiment was carried out after Saltveit study (Saltveit 2016). However, due time limitation, the microalgae culture (chlorella) was observed for 16 hours only. The $\mathrm{O}_{2}$ release was monitored and measured through respirometer in the photosynthesis process. The eosin used in the measurement plays as an indicator of oxygen amount (speed of $\mathrm{O}_{2}$ rate) produced by the photosynthesis process. In particular, the chlorella can significantly contribute to the air purification process. By the photosynthesis of algae, $\mathrm{CO}_{2}$ is required and then $\mathrm{O}_{2}$ is released. Rosenberg's studies revealed that functional-form, taxonomic group, to which a species belongs, and the nutrient provided, do not affect the photosynthetic quotient (PQ) (Rosenberg et al. 1995). Thus, the increase of oxygen will definitely increase the indoor air quality regardless of the type of algae, which will be grown in the photo-bioreactor.

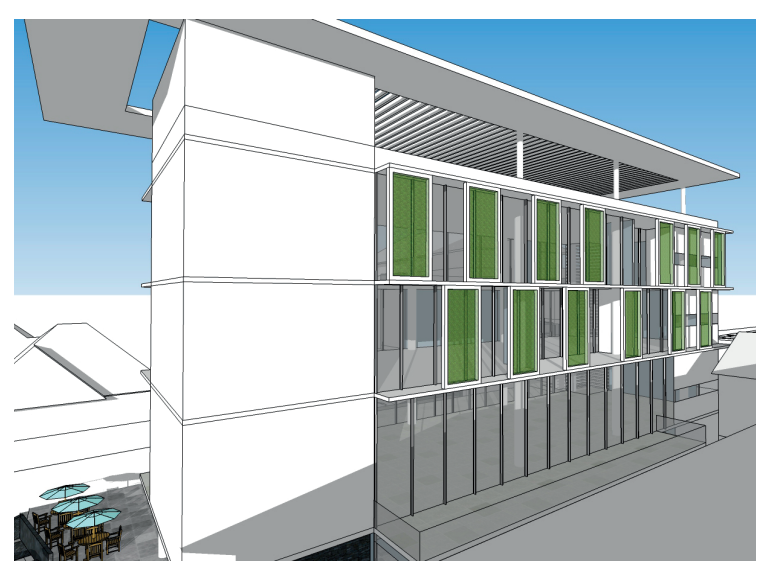

Fig. 4b. The application of algae photo-bioreactor in the building façade

As mentioned, indoor temperature and total energy use in the building will be the focus of the experiment. After having the result of the third type, the algae photo-bioreactor, and the result of the computer simulation models will be assessed and evaluated. The use of photo-bioreactor will hypothetically reduce the sun exposures and influence the indoor temperature (solar heat gain). In the final stage, the result of those temperature and illuminance measurements will be analyzed in regard to the total amount of energy consumption. Based upon data interpretation, the simulation results could give considerations and suggestions in the realm of architectural design; how far the building (façade) design is affected by considerations, such as energy consumption pattern, environmental condition and energy cooling cost.

\section{Building façade analysis}

For the computer simulation, several thermal zones are applied in the building, which has been designated according to its function. The use of air conditioning in this experiment is required to measure the amount of total energy (in Giga Joules) in the building with OS-EP software. For this experiment, the third and fourth floors of the building were covered by shading device. These two floors, which accommodate the main facilities (co-working spaces and rental offices), will be tested and selected as the focus of calculation. The analysis of the three building façade systems will be described as follows:

The simulation device of algae photo-bioreactor will be used to measure the indoor temperature and solar radiation. The device has been constructed and modified in accordance with Figure 4a. Chlorella algae are used in this experiment because of its character, which could grow tougher in many conditions such as un- 
foreseen weather or unstable medium. The algae with sterilized water medium contain $\mathrm{NaNO}_{3}, \mathrm{~K}_{2} \mathrm{HPO}_{4}$, and $\mathrm{MgSO}_{4}$ as their food were planted in a glass box that is connected to a black box as seen in Figure $5 \mathrm{a}$. As mentioned, data loggers to measure and record the indoor temperature, as well as solar radiation, were installed inside the black box. This algae photo-bioreactor model is now placed on the rooftop and is facing west, so it could represent the actual building design (see Fig. 5b). This experiment would take four weeks to investigate how the algae photo-bioreactor could perform in the real condition of Bandung weather. The scheme in the

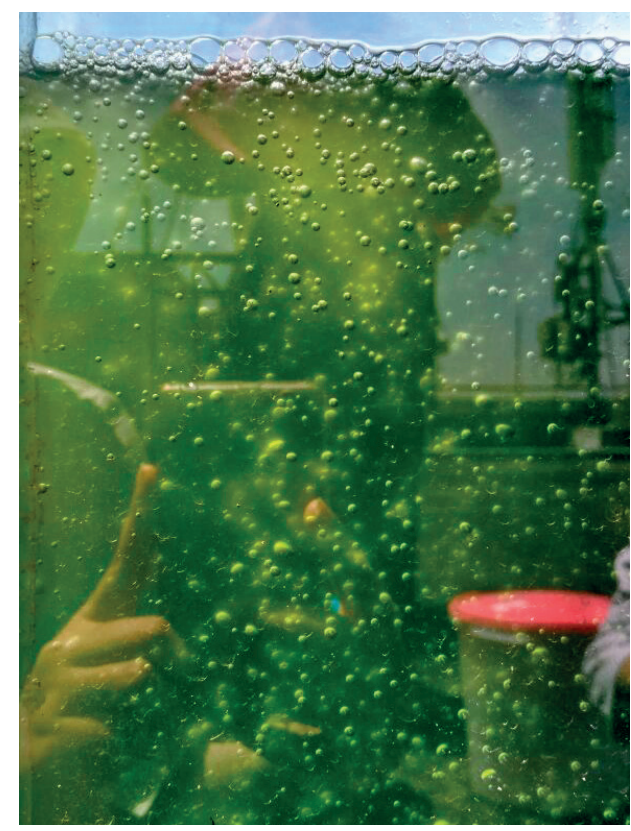

Fig. 5a. The algae consume oxygen produced by aerator in the photo-bioreactor building design from the algae pond in the basement to the algae photo-bioreactor panels in level three and four in the building façade could be seen in Figure 6.

\section{Result and discussions}

\section{Temperature difference $(\Delta \mathrm{T})$}

Based on yearly average temperature from computer simulation, for the case brise-soleil as secondary skins, temperature differences $(\Delta \mathrm{T})$ between indoor and outdoor temperature was recorded ca. $3.412{ }^{\circ} \mathrm{C}$. Meanwhile, the use of horizontal fixed shading device had the amount of temperature difference $(\Delta \mathrm{T}) \mathrm{ca} .3 .52^{\circ} \mathrm{C}$.

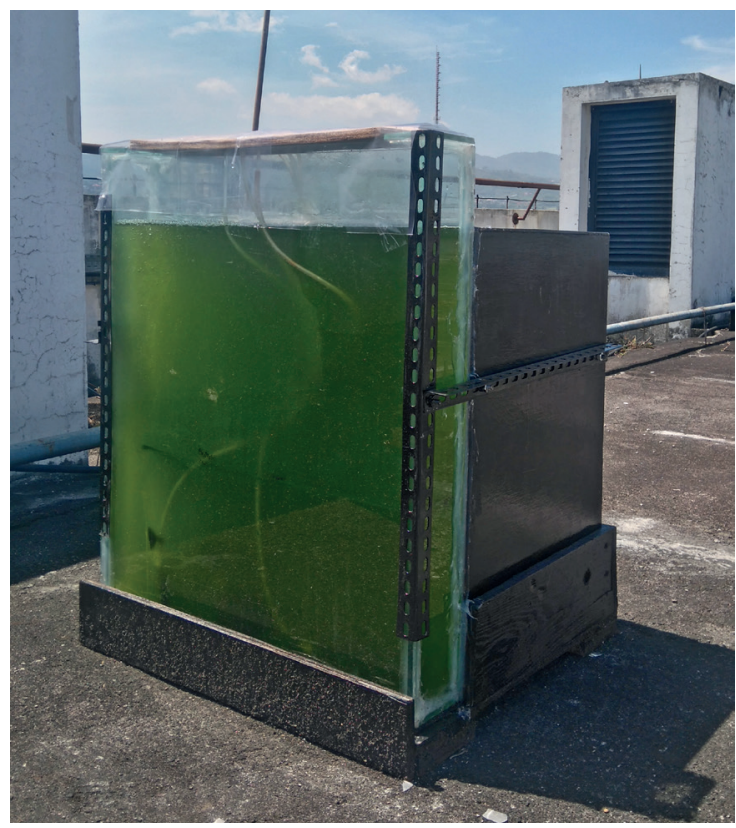

Fig. 5b. The application of algae photo-bioreactor in the building façade

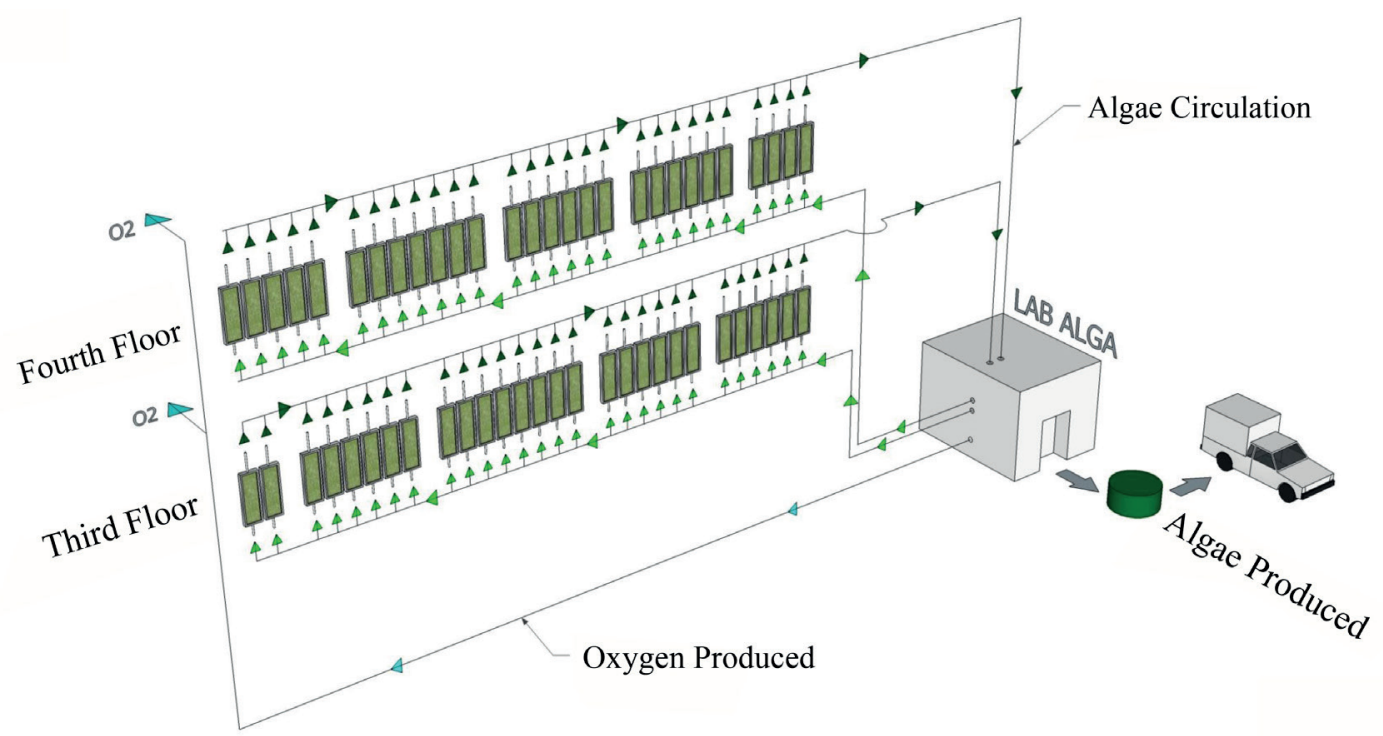

Fig. 6. The model of photo-bioreactor scheme in ITB Innovation Park 
The measurement took place on 12 September 2017, and lasted for 24 hours. The result was resumed on 13 September 2017 at the same time. The simplified model measurement result showed that the maximum indoor temperature occurred at $1.22 \mathrm{p} . \mathrm{m}$. of $42.1^{\circ} \mathrm{C}$ while the minimum was occurred at $4.52 \mathrm{a} . \mathrm{m}$. and $5.52 \mathrm{a} . \mathrm{m}$. of $19.6{ }^{\circ} \mathrm{C}$. The average of temperature difference $\mathrm{s}(\Delta \mathrm{T})$ between indoor and outdoor within 24 hours at that time was $6.447^{\circ} \mathrm{C}$. The chart also clearly shows that in certain times (between 4.22 p.m. until 6.22 a.m.) the outside temperature were lower than the interior of the model. In contrary, after 6.52 a.m. when the outside temperature was higher, the indoor temperature revealed lower numbers (see Fig. 7). This result indicates that the algae photo-bioreactor model could decrease the indoor temperature when the outside temperature was higher. Besides that, it was assumed that the model could increase the indoor temperature when the outdoor temperature were low by releasing heat from the algae photo-bioreactor panel that was exposed by the solar radiation in the daytime.

Thus, if one compares the temperature difference of the three alternatives of building façade, such as brisesoleil, horizontal fixed shading device and algae photo-bioreactor, it can be concluded that photo-bioreactor has the highest temperature difference, i.e. $6.447^{\circ} \mathrm{C}$. Meanwhile, the temperature differences based on computer simulation were recorded as follows, brise-soleil of $3.412^{\circ} \mathrm{C}$, horizontal fixed shading device of $3.52^{\circ} \mathrm{C}$. Given this findings, the use of energy cooling for photo-bioreactor is significantly lesser that the other two building façade systems.

\section{Illuminance test (lux)}

The direct measurement (data logger) was done from 06.22 a.m. till 05.52 p.m. in the interior of the simplified model, and the average of the indoor illuminance of 1,049.176 lux was digitally recorded. Thus, according to SNI 2001, the amount meets the requirement of illuminance for an office building.

Figure 8 shows that there is a significant difference of illuminance between outdoor and indoor. However, this figure does not show the result of the night time since there was no sunlight. The highest illuminance in the outdoor was at 11.52 a.m. of 110,800 lux while the indoor was at 3.22 p.m. of 5,189 lux. However, when the outdoor illuminance recorded by the data logger outside the model, it does not mean that the indoor would be the highest as well, because it depends on the material and opening position of the building. In this model, the glass aquarium contained water and algae was facing west side, so when the sun is almost set (after 3 p.m.) in the west, the illuminance in the indoor model would be higher. Although the algae photo-bioreactor model could reduce more than $90 \%$ of daylight, the amount of illuminance in the indoor still comply the standard of daylight requirements for an office building. As for irradiance, the trends are almost the same as illuminance. More than $99 \%$ of the solar radiation could be blocked by the algae photo-bioreactor. The average of solar radiation inside the model was $0.009 \mathrm{~W} / \mathrm{m}^{2}$ while the outdoor in daytime was $12.164 \mathrm{~W} / \mathrm{m}^{2}$. The maximum solar radiation that fenestrated into the building was at $3.22 \mathrm{p} . \mathrm{m}$. with $0.06 \mathrm{~W} / \mathrm{m}^{2}$.

The measurement of the indoor irradiance value could also contribute to increasing the ability of al-

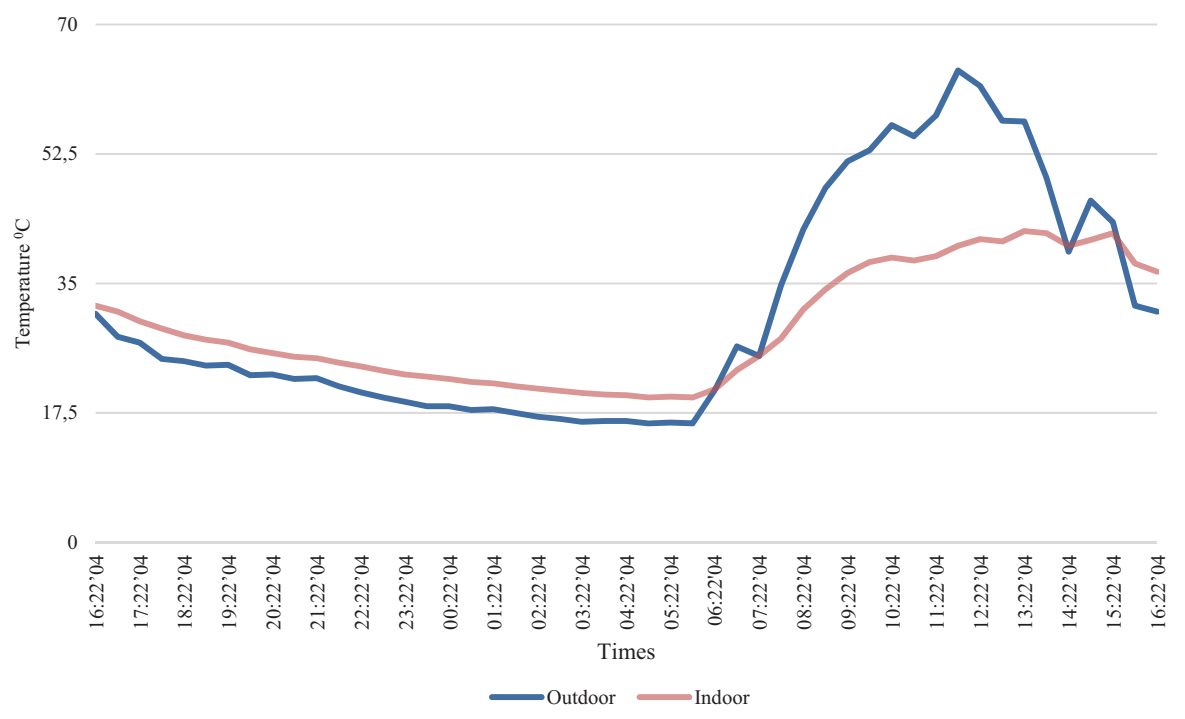

Fig. 7. Temperature measurement 


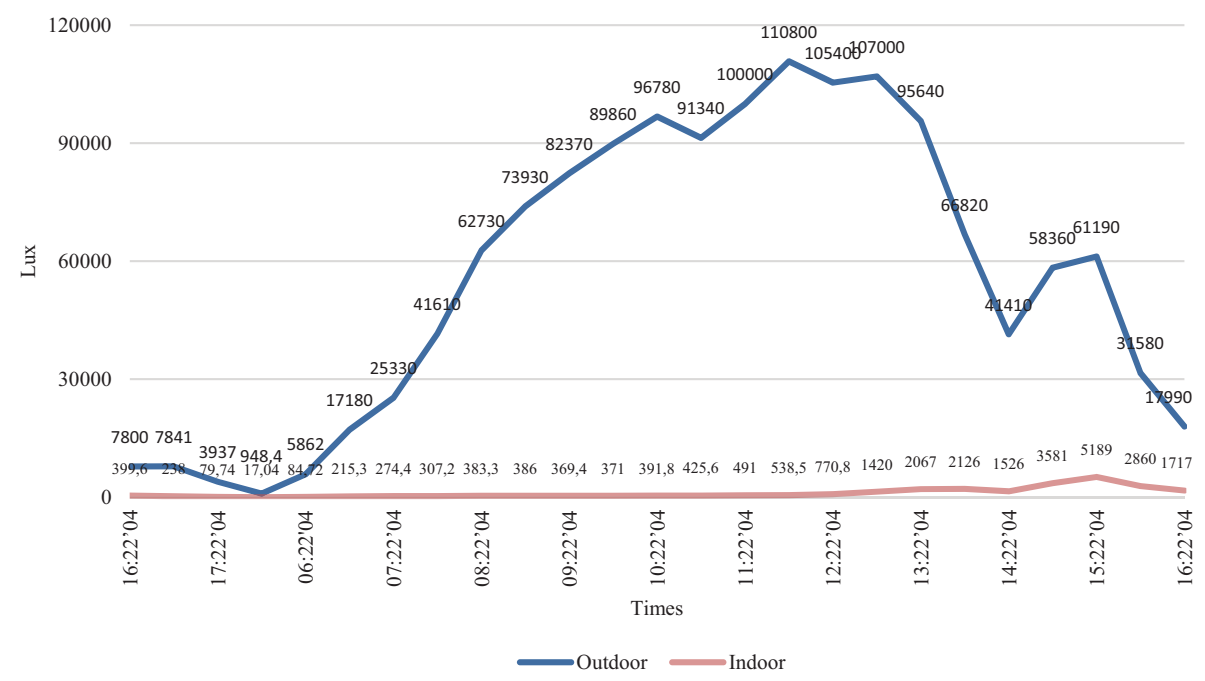

Fig. 8. Illuminance measurement

gae photo-bioreactor in reducing the solar heat gain. Furthermore, that will have a significant impact on the use of energy. Following this, it can thus confirm the ability of the photo-bioreactor (algae) and property material to absorb the solar radiation. Given the circumstances above, the use of secondary skin, i.e. brise-soleil, horizontal fixed shading device and photo-bioreactor, as part of building façade system might influence the performance of the building façade.

\section{Oxygen release}

According to the measurement process, it was identified two results of $\mathrm{O}_{2}$ production, the highest amount was yielded at T12 between $07.00-08.00$ a.m., while the lowest harvest took place at T6 between 01.00-02.00 a.m. The decreasing amount of oxygen was influenced by the lack of sunlight intensity (cf. Oakley et al. 2012). Based upon 16 hours observation, it was recorded that the production of oxygen release ca. $4.83 \mathrm{ml} /$ hour/l microalgae culture (chlorella). The microalgae culture can significantly contribute to the purification process, in which by the photosynthesis, $\mathrm{CO}_{2}$ is required and then $\mathrm{O}_{2}$ is released (cf. Rosenberg et al. 1995). Thus, as previously stated, the increase of oxygen will definitely increase the indoor air quality (cf. Fig. 9).

\section{Total energy use analysis}

Based on the simulations, the result shows that the amount of cooling energy (district cooling) for whole building with horizontal fixed shading device is $1,009.80 \mathrm{GJ}$, and it is lesser compared to the building with brise-soleil (1,020.16 GJ). This result (cf. Fig. 10) proves that the passive architecture design such as shading devices or secondary skins could help the building in hot and humid climate to reduce the cooling energy. As measured, the photo-bioreactor has the significant/highest temperature difference, i.e. $6.447{ }^{\circ} \mathrm{C}$. Meanwhile, the temperature differences based on computer simulation were recorded as follows, brise-soleil of $3.412^{\circ} \mathrm{C}$, horizontal fixed shading device of $3.52^{\circ} \mathrm{C}$. With these findings, the consumption of energy cooling (district cooling) for the build-
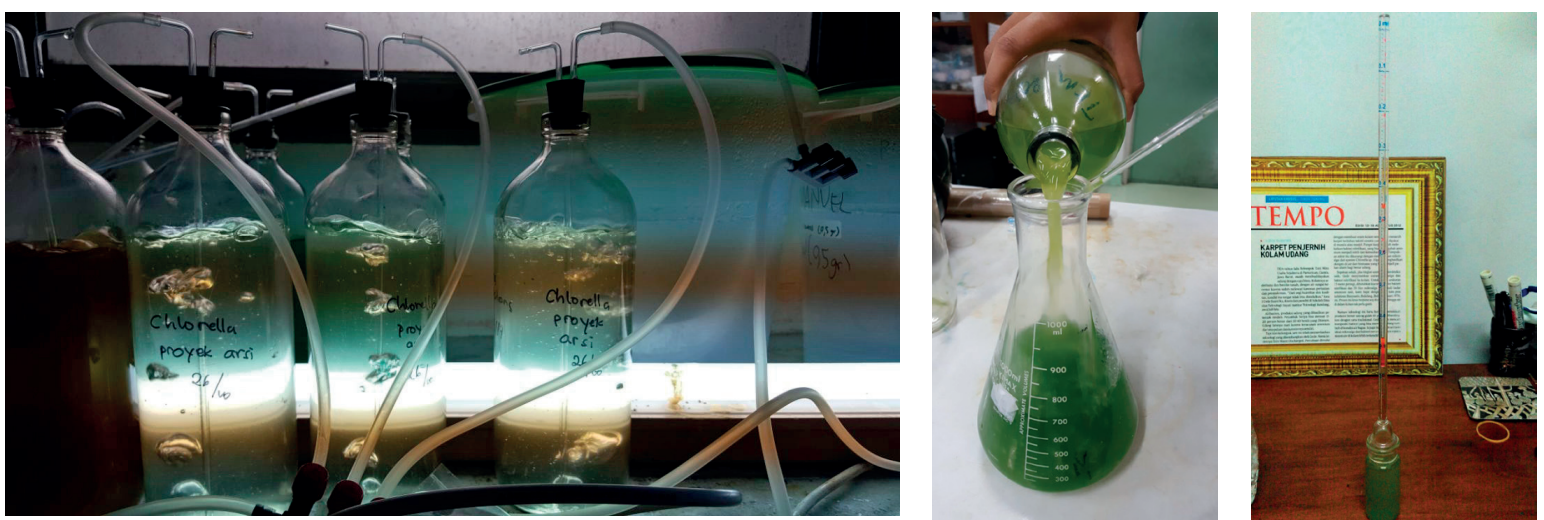

Fig. 9. The experiment to calculate Oxygen production from algae by using respirometer 


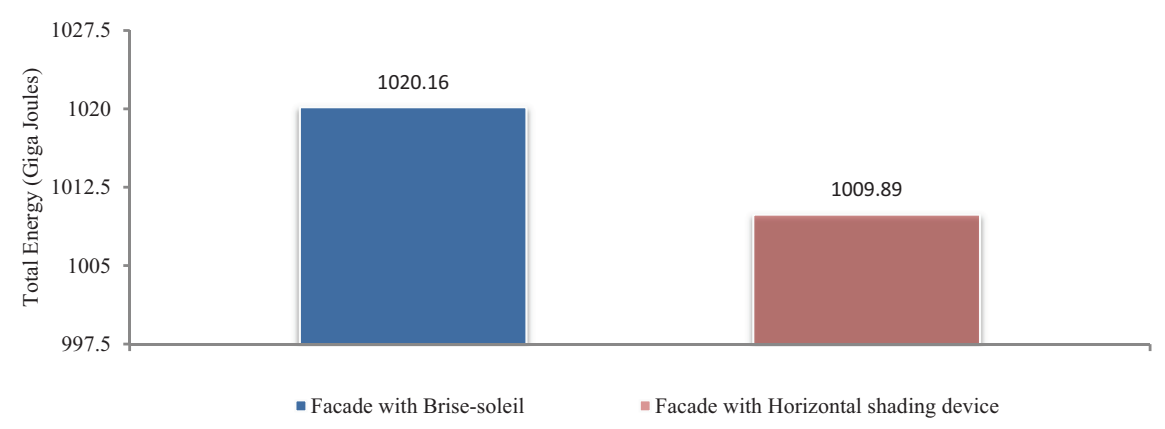

Fig. 10. District cooling for whole building

ing with algae photo-bioreactor will be less, comparing to the use of brise-soleil and horizontal fixed shading device. Following this, the use of algae photo-bioreactor as secondary skin, which will be mounted on the west façade, will not only contribute to in reducing solar heat gain but also protects the critical building façade from the sun exposure.

\section{Concluding remarks}

The ITB Innovation Park project reveals some evidences on considerations in designing building façade. The building is uniquely located, in an infill of a specific urban setting that is associated with existing historic urban quarter. Based upon the investigation of the glass façades of the building with the east-west orientation, a special treatment is needed, especially in reducing the sun exposure. To some extent, this will highlight one of the design approaches in the historic urban area, i.e. contextual juxtaposition.

The use of secondary skins, such as brise-soleil, horizontal fixed shading device and algae photo-bioreactor as part of building façade system may contribute significantly both to the design approach and its associations with choice of building material, and the supply of alternative potential energy. Ultimately, the evidences may be used as justification for environmentally friendly principles for architectural design.

The simulation results show that the use of algae photo-bioreactor has yielded significant temperature difference $(\Delta T)$. From the findings, it can be concluded, that the use of algae photo-bioreactor on the critical building façade will significantly contribute to reduce of indoor temperature, in which the solar heat gain will be respectively decreased, and the secondary skin of algae will also protect against the sun exposure. Comparison between three types of building façade has been articulated that photo-bioreactor not only contributed to reduce the use of energy cooling, but also through the oxygen release will positively influence the indoor air quality of the building. The result of building simulation can be verified, once the building is constructed completely by the end 2018 .

Nevertheless, the calculation of temperature differences through computer simulation is strongly dependent on the accountability of the collected data, and some assumptions in regard to the calculation of daily temperature. Moreover, since there is no available local/Bandung weather data, the simulation with OS-EP software is still dependent to Singapore weather data. The lack of such a data must be anticipated in order to conduct further research on energy performance assessment.

\section{Acknowledgements}

Special thanks and appreciations are dedicated to $\mathrm{Dr}$ Gede Suantika and Reskha Handayani, S.T. (Microbial Biotechnology Research Group), School of Life Sciences and Technology for his supports and thoughtful remarks on algae photo-bioreactor, and Suhendri, MSc from the Building Technology Research Group, School of Architecture, Planning and Policy Development, Institut Teknologi Bandung for his supports on the computer simulation, calculation and modeling.

\section{Funding}

The authors would like to express sincere gratitude to ITB for the financial support grant. The research project has been funded through the ITB P3MI (Program Penelitian Pengabdian Masyarakat dan Inovasi), which had been allocated by Institut Teknologi Bandung.

\section{References}

Carmona, M.; Heath, T.; Taner, O.; Tiesdell, S. 2010. Public places - urban spaces: the dimensions of urban design. Abingdon: Routledge.

Kim, K.-H. 2013. Beyond green: growing algae façade, ARCC Conference Repository, 500-505.

Oakley, C. A.; Hopkinson, B. M.; Schmidt, G. W. 2012. A modular system for the measurement of $\mathrm{CO} 2$ and $\mathrm{O} 2$ gas flux and photosynthetic electron transport in microalgae, Limnology and Oceanography: Methods 10: 968-977.

https://doi.org/10.4319/lom.2012.10.968 
Orbaşli, A. 2008. Architectural conservation: principles and practice. Oxford: Backwell Publishing.

Riza, M.; Doratli, N. 2015. The critical lacuna between contextuality juxtaposed and freestyle building in historic settings, Journal of Architectural and Planning Research 32(3): 234-257.

Rosenberg, G.; Littler, D. S.; Littler, M. M.; Oliveira, E. C. 1995. Primary production and photosynthetic quotients of seaweeds from São Paolo State, Brazil, Botanica Marina 38: 369-377. https://doi.org/10.1515/botm.1995.38.1-6.369

Saltveit, Jr, M. E. 2016. Measuring Respiration. University of Florida [online], [cited 27 October 2017]. Available from Internet: http://irrec.ifas.ufl.edu/postharvest/HOS_5085C/ Lectures/03\%20Respiration-Introduction\%20\&\%20 Measurement\%20-\%20Presenter\%20output/Measuringrespiration\%20(Saltveit).pdf

Schmidt, L. 2008. Architectural conservation: an introduction. Berlin/Bonn: Westkreuz-Verlag GmbH.

SNI6197-2001. Konservasi Energi Pada Sistem Pencahayaan. Indonesian Standard.

Sotoudeh, H. W.; Abdullah, W. M. Z. 2013. Contextual preferences of experts and residents: issue of replication and differentiation for new infill design in urban historical context, World Applied Sciences Journal 21(9): 1276-1282.

Stone, D. 2012. Can algae power the future. Powering the Future, Future Power. National Geographic, Washington D.C.

Tiesdell, S.; Taner, O.; Heath, T. 1996. Revitalizing historic urban quarters. Oxford: Architectural Press.

U.S. EIA. 2017. Annual energy outlook 2017 [online], [cited 31 October 2017]. Energy Information Administration. Available from Internet: https://www.eia.gov/outlooks/aeo/ pdf/0383(2017).pdf

Weeks, K. D.; Grimmer, A. E. 1995. The Secretary of the Interior's standards for the treatment of historic properties with the guidelines for preserving, rehabilitating, restoring and reconstructing historic buildings [online], [cited 27 May 2017]. Technical Preservation Services. Available from Internet: http://www.nps.gov/tps/standards/four-treatments/treatment-guidelines.pdf.

Wells, J. C. 2010. Valuing historic places: traditional and contemporary approaches [online], [cited 4 September 2017]. Roger Williams University. Available from Internet: http://docs. rwu.edu/saahp_fp/22.

Wen, H.; Chiang, M. S.; Shapiro, R. A.; Clifford, M. L. 2007. Building energy efficiency, why green buildings are key to Asia's future. Environmental policy and industry in China. Asia Business Council, Hongkong.

Wohlleben, M.; Meier, H. R. 2003. Nachhaltigkeit und Denkmalpflege Beiträge zu einer Kultur der Umsicht. Zurich: Hochschulverlag AG an der ETH Zürich (in German).

Yeang, K. 2008. Biofuel from algae, architectural design [online], [cited 26 May 2017]. Wiley Online Library. Available from Internet: http://onlinelibrary.wiley.com/doi/ 10.1002/ ad.689/abstract

Yeang. K. 2006. Ecodesign: a manual for ecological design. London: John Willey and Son, Ltd.

\section{WIDJAJA MARTOKUSUMO}

(1966) is professor in Architecture and Urban Heritage Conservation, and currently is dean of the School of Architecture, Planning and Policy Development (SAPPD) Institut Teknologi Bandung (ITB). In 1999 he was awarded a Doktor-Ingenieur
(Dr-Ing.) degree in urban planning and design from the Fachbereich Stadt-/Landschaftsplanung, Universität Gesamthochschule Kassel, Germany. He was also a visiting assistant professor at the Fakultät Architektur, Fachchschule Erfurt in Winter Semester 2008/2009. He has received Melbourne Asia Visiting Fellowship Award 2015-2016 at Melbourne School of Design (MSD), University of Melbourne, Australia. Through his teaching, research, publication and professional engagements, he has contributed to the study of architectural conservation, urban heritage conservation, and urban design in Indonesia. Since 2013 he becomes the chair of the architectural design research group at the SAPPD ITB.

\section{DONNY KOERNIAWAN}

is lecturer and researcher at Department of Architecture, School of Architecture, Planning, and Policy Development, Institut Teknologi Bandung, Indonesia. He holds $\mathrm{PhD}$ degree from The University of Kitakyushu, Japan, Faculty of Environmental Engineering, 2015. He is Urban Microclimate Modeling and Building Energy specialist with extensive experience in Urban and Building Energy simulation, development of ventilated city model and natural ventilated building performance for human thermal comfort and walkability city, inclusive of major contributions to new cities design in some cities in Indonesia. He is now working with SHERA (Sustainable Higher Education Research Alliances) USAID, from 2017-2021, to develop building integrated photovoltaic in urban and remote area of Indonesia.

\section{HERU W. POERBO}

was born in Bandung-Indonesia on September $6^{\text {th }}$, 1963. Currently is the head of graduate program in architecture and urban design, at the School of Architecture, Planning and Policy Development, (SAPPD) Institut Teknologi Bandung (ITB). He obtained Sarjana/Insinyur degree in architecture from ITB in 1988, and Master of Urban and Regional Planning from the University of Hawaii, USA in 1992. In 2001 he was awarded a Doktor-Ingenieur from Universität Kaiserslautern, Germany. His research interest includes Urban design and urbanism; transit oriented development, computer application in urban design

\section{NISSA A. ARDIANI}

is currently an academic and research assistant in Architecture Design and Research Group, at the School of Architecture, Planning and Policy Development (SAPPD), Institut Teknologi Bandung (ITB). She got her Bachelor's degree in Architecture from Institut Teknologi Bandung in 2011, and obtained her Master's Degree in Sustainable Building Technology from University of Nottingham at 2015. Research interests: Sustainable building technology application in hot and humid climate region, Building Performance Simulation, Passive Design Architecture, and Building Retrofit.

\section{SUSAN H. KRISANTI}

is currently an academic assistant at School of Architecture, Planning and Policy Development (SAPPD), Institut Teknologi Bandung (ITB). Assisting Tutor for Master in Landscape Architecture Program (ITB). Bachelor in Architecture from ITB in 2011. She was graduated Master in Landscape Architecture from Royal Melbourne Institute of Technology (RMIT) 2016. Research Interest: Sustainable Urban Landscape Design. 